\title{
1 Mischungen: EIN MÄDCHeN GEHT AN LAND
}

Das Recht ist erdhaft und auf die Erde bezogen. [...] Das Meer kennt keine solche sinnfällige Einheit von Raum und Recht, von Ordnung und Ortung. [...] Das Meer ist frei. ${ }^{1}$ (Carl Schmitt) Es ist also durchaus eine Frage: Was ist unser Element? Sind wir Kinder des Landes oder der See?² (Carl Schmitt)

Was am Rande liegt und was die Mitte sei, ist eine Frage des Standpunktes. ${ }^{3}$ (Karsten Witte)

\section{Irdisches Glück}

In Filmmelodramen der NS-Zeit, und nicht nur bei Veit Harlan, gehen die Frauen gewöhnlich am Ende ins Wasser. In Werner Hochbaums EIN MÄDCHEN GEHT AN LAND (D 1938) nimmt Erna Quandt (Elisabeth Flickenschildt) den umgekehrten Weg. Als ihr Verlobter Hein Groterjahn (Hans Mahler) in einer Sturmnacht den Untergang seines Frachters nicht überlebt, verlässt die Tochter eines Hamburger Küstenschiffers das vertraute väterliche Schiff, um sich in Hamburg auf Stellungssuche zu begeben. Der Traum vom zukünftigen Eheglück auf See hat sich zerschlagen. Ihren Platz an Bord der „Katharina Quandt“ an der Seite von Vater und Brüdern wird die Verlobte eines der Brüder einnehmen. Durch die Vermittlung ihrer Tante (Claire Reigbert) findet sie in Blankenese eine Anstellung als Hausmädchen bei dem Reeder Walter Sthümer (Carl Günther) und seiner aus Wien stammenden Frau Lisa (Maria Faudler), deren bisherige Zofe es zurück in Österreichs Hauptstadt zieht. ${ }^{4}$ Erna lebt zunächst still und zurückgezogen, ihren Lebensmut bezieht sie aus einem mitgebrachten Seemannskalender mit Sinnsprüchen von Gorch Fock. Neben dem Haushalt der Sthümers, in den mit Erna gediegene hanseatische Lebensart Einzug hält, rückt sie auch die Ehe des voneinander entfremdeten Paares ins Lot: Sie setzt den „Hausfreund“ Lisa Sthümers, Rechtsanwalt Dr. Ried (Franz Arzdorf), vor die Tür und wendet einen Trick an -

1 Carl Schmitt: Das Recht als Einheit von Ordnung und Ortung [1950]. In: Jörg Dünne und Stephan Günzel (Hg.): Raumtheorie. Grundlagentexte aus Philosophie und Kulturwissenschaften. Frankfurt am Main 2006, S. 409-419, Zitat S. 409f.

2 Carl Schmitt: Land und Meer. Eine weltgeschichtliche Betrachtung [1942]. Stuttgart 2001, S. $10-11$.

3 Karsten Witte: Hochbaum, der Periphere: ein Zentraler. Notiz zu MoRgen Beginnt DAS Leben (1933). In: Kinoschriften. Jahrbuch der Gesellschaft für Filmtheorie, Bd. 3. Wien 1992, S. 5-14, Zitat S. 5.

4 Der „Anschluss“ Österreichs an das Deutsche Reich erfolgte im März 1938 während der Arbeiten am Drehbuch zu diesem Film.

Ә OpenAccess. (c) 2020 Michael Wedel, publiziert von De Gruyter. (cc) BY-NC-ND Dieses Werk ist lizenziert unter der Creative Commons Attribution-NonCommercial-NoDerivatives 4.0 License. 
Teilquarantäne wegen Mottenbefalls -, um die Eheleute wieder einer gemeinsamen Schlafstatt zuzuführen.

Erna selbst hat in dieser Hinsicht auch an Land weitaus weniger Glück: Ihr Verehrer Jonny Hasenbein (Carl Kuhlmann) entpuppt sich als Heiratsschwindler, der es nur auf ihr Geld abgesehen zu haben scheint. Als eine der von ihm Geschädigten sein Notizbuch entwendet und ihm auf diese Weise auf die Schliche kommt, wird Jonny verhaftet. Genug, um Erna schließlich doch mit dem Gedanken spielen zu lassen, sich in die Elbe zu stürzen. Die Zuneigung der Nachbarskinder von Onkel und Tante bewahrt sie vor diesem Schritt. Am Ende willigt sie - eher den drei Kindern als dem Mann zuliebe - in die Ehe mit deren verwitwetem Vater, dem Schiffszimmermann Friedrich Semmler (Herbert E. A. Böhme), ein und findet auf diese Weise doch noch ihren Platz an Land.

Zur vermeintlich versöhnlichen Schlussfigur rundet sich damit eine Form „,irdischen Glücks“, die fern aller romantischen Vorstellungen angesiedelt ist. Sie verlängert vielmehr das dem Wohl von Mann und Familie dienende Selbstverständnis der Protagonistin von der den Vater und Bruder Umsorgenden über die Dienstmädchenexistenz im Hause Sthümer und die bereitwillig ihre Ersparnisse einem windigen Geschäftsmann opfernde Freundin in die eheliche Zukunft. Selbst wenn man Karsten Witte in seiner Lesart zustimmt, dass es bei der Bewertung der Figur Erna Quandts weniger von Belang sei, sie „ins Mutterklischee gezwängt“ zu sehen, als vielmehr, dass sie „zuvor alle Entscheidungen als autonome Frau“ getroffen habe, der Film also insofern eine „Abweichung von der Regel“ darstelle ${ }^{5}$ - festzuhalten bleibt doch, dass diese vermeintlich autonom gefällten Entscheidungen sich sämtlich in eine Rollenschablone fügen, die „echte Weiblichkeit“ mit der Bereitschaft zum dienstwilligen Altruismus zur Deckung bringt. ${ }^{6}$

Überhaupt ist von Gefühlen und Romantik in diesem eigenartigen Melodrama kaum eine Spur vorhanden. Wo sich bei der Heldin in Bezug auf Jonny Hasenbein Ansätze dazu finden (und sie ins Verderben zu führen drohen), versickern sie schnell in Hilfsbereitschaftsgesten und Zweckmäßigkeitsüberlegungen. Mit der finalen Ankunft im „sicheren Hafen“ einer Vernunftehe und als Ersatzmutter

5 Karsten Witte: Film im Nationalsozialismus. In: Wolfgang Jacobsen, Anton Kaes und Hans Helmut Prinzler (Hg.): Geschichte des deutschen Films. Stuttgart und Weimar 1993, S.119-170, hier S. $144 \mathrm{f}$.

6 Vgl. Ingrid Wittmann: „Echte Weiblichkeit ist ein Dienen“. Die Hausgehilfin in der Weimarer Republik und im Nationalsozialismus. In: Frauengruppe Faschismusforschung (Hg.): Mutterkreuz und Arbeitsbuch. Zur Geschichte der Frauen in der Weimarer Republik und im Nationalsozialismus. Frankfurt am Main 1981, S. 15-48. 
dreier Kinder ist Erna endgültig auf dem Boden nüchterner und naheliegender Tatsachen angelangt, den sie auch zuvor selten einmal verlassen hat.

Die Art und Weise, auf die das geschieht, mag ganz im Sinne dessen gewesen sein, was der NS-Staatstheoretiker und Philosoph Carl Schmitt etwa zur gleichen Zeit seiner Tochter Anima über das dem Menschen (geschlechtsunabhängig) Gemäße mit in den Schlaf gegeben hat: Erna wird zu einem „Landwesen“, das sich nicht mehr nach der schwankenden Existenz auf See sehnt, sondern auf der „festgegründeten Erde“ bewegt und lernt, von dort seinen Blickpunkt auf die Welt zu gewinnen. ${ }^{7}$ Das sprichwörtlich Bodenständige bestimmt die „Eindrücke“ und die „Art, die Welt zu sehen“. ${ }^{8}$ Der „elementare Gegensatz von Land und Meer“ ", ${ }^{9}$ in dem sich der Zwiespalt zwischen faktischer Immanenz und ungewisser Transzendenz spiegelt, löst sich aus dieser Warte für Erna darin auf, dass ihr Dasein nun endgültig ins Diesseitige „gewendet“ ist. An die Stelle eines in anderen Beispielen des melodramatischen Genres so oft evozierten und spektakulär verfehlten „himmlischen Glücks“ wird hier mit Nachdruck ein „,irdisches“ gesetzt: „Unser ganzes diesseitiges Dasein, Glück und Unglück, Freude und Leid, ist für uns das ,irdische ${ }^{6}$ Leben und - je nachdem - ein irdisches Paradies oder ein irdisches Jammertal“, heißt es bei Schmitt. ${ }^{10}$ Und schon Hegel glaubte zu wissen, und wird dafür von Schmitt zitiert, dass „die Erde, fester Grund und Boden“ keineswegs - wie etwa das belebende Element des Meeres - den geeigneten Nährboden für romantische Liebesvorstellungen und idealisierende Selbstentwürfe abgibt, sondern schlicht für das „Prinzip des Familienlebens“ steht. ${ }^{11}$

Insgesamt scheint den Handlungskonflikten des Films ein Dezisionismus zugrunde zu liegen, der die Sphären von Land und Meer, Mann und Frau, Gemeinschaft und Individuum sorgsam in differenzielle Muster der geopolitischen, gesellschaftlichen und geschlechtlichen (Rollen-)Verteilung anordnet. Die Entfesselung der Widersprüche zwischen diesen Sphären, die Melodramen ansonsten so exzessiv zu inszenieren und am transgressiven Begehren ihrer Figuren auszuagieren verstehen, wirkt hier vielleicht deshalb derart zurückgenommen, weil die von Witte angesprochene Entscheidungsmacht der weiblichen Hauptfigur - selbst noch nach dem Wurf aus der vorgezeichneten Lebensbahn der

7 Schmitt: Land und Meer, S. 16. Die Widmung des Buches gibt Auskunft darüber, dass die in ihm enthaltenen Betrachtungen von ihrem Verfasser zunächst dessen Tochter Anima erzählt wurden.

8 Schmitt: Land und Meer, S. 16.

9 Schmitt: Land und Meer, S. 16.

10 Schmitt: Land und Meer, S. 7.

11 Georg Wilhelm Friedrich Hegel: Grundlinien der Philosophie des Rechts, § 247, zit. nach Schmitt: Land und Meer, S. 108. 
„Seemannsbraut“ - die vorgegebenen Verhaltensmuster kaum einmal überschreitet.

Es scheint fast so, als hätte Erna Quandt die Prämissen der „Bedeutung des Einzelnen“ innerhalb eines übergeordneten Gemeinwesens, von Carl Schmitt bereits 1914 aufgestellt und zur Zeit des Nationalsozialismus systematisch zur politischen Theorie ausgefaltet, ${ }^{12}$ nicht weniger internalisiert als die Maximen des 1916 bei der Seeschlacht vor dem Skagerrak gefallenen Schriftstellers Gorch Fock. Solange laut Schmitt - und wie im Melodrama klassischerweise der Fall - die Betrachtung des „leiblich konkrete[n] Individuum[s] [...] sich nicht über die materielle Körperlichkeit“ erhebt, bleibt dieses Individuum „eine gänzlich zufällige Einheit, ein zusammen gewehter Haufen von Atomen, dessen Gestalt, Individualität und Einzigkeit keine anderen sind, wie des Staubes, der vom Wirbelwind zu einer Säule gefügt wird“. ${ }^{13}$ Einen über das rein Natürliche und Kreatürliche hinausgehenden Sinn erlange das Individuum erst, wenn es „die [...] subjektive empirische Wirklichkeit“ der eigenen Individualität negiere und sich der Erfüllung der vom Gemeinwesen vorgegebenen, „objektiv gültige[n] Norm“14 widme: Das „Individuum [...] als empirisches Einzelwesen verschwindet, um vom Recht und dem Staat, als Aufgabe, Recht zu verwirklichen, erfasst zu werden und selbst seinen Wert in dieser abgeschlossenen Welt nach ihren eigenen Normen zu empfangen“. ${ }^{15}$ Dies geschehe „nicht, um den Einzelnen zu vernichten, sondern um aus ihm etwas zu machen“. ${ }^{16}$ Daher auch dürfe „das Subjekt der Autonomie“ eben nicht „das empirische, zufällige, der Sinnenwelt angehörende Individuum sein“, da „die Fähigkeit, Subjekt der Autonomie zu werden, sich nicht aus den empirischen Tatsachen, sondern aus der Vernunft“ ergebe: „Nur insofern es ein vernünftiges Wesen ist, hat es Autonomie, ist sein Wille ein allgemein gesetzgebender." 17

Vor diesem Hintergrund erscheint die „autonome Frau“ Erna Quandt weniger als melodramatisch leidende und nach dem Diktat ihres Begehrens handelnde Heroine denn als „ethisches Gebilde““. ${ }^{18}$ Nicht umsonst ist auf die „ideologischen Implikationen der Story“ von EIN MÄDCHEN GEHT AN LAND hingewiesen wor-

12 Zur Entwicklung des Begriffs bei Schmitt vgl. André Brodocz: Die politische Theorie des Dezisionismus: Carl Schmitt. In: André Brodocz und Gary S. Schaal (Hg.): Politische Theorien der Gegenwart I. Opladen 2006, S. 277-311.

13 Carl Schmitt: Der Wert des Staates und die Bedeutung des Einzelnen [1914]. Berlin 2004, S. 101.

14 Schmitt: Der Wert des Staates und die Bedeutung des Einzelnen, S. 89.

15 Schmitt: Der Wert des Staates und die Bedeutung des Einzelnen, S. 10.

16 Schmitt: Der Wert des Staates und die Bedeutung des Einzelnen, S. $10 \mathrm{f}$.

17 Schmitt: Der Wert des Staates und die Bedeutung des Einzelnen, S. 89.

18 Schmitt: Der Wert des Staates und die Bedeutung des Einzelnen, S. 88. 
den, die der herrschenden NS-Weltanschauung insofern entsprächen, als sie den schmerzhaften, im Schmitt’schen Sinn „dezisionistischen“ Ablösungsprozess Ernas von der vertrauten nautischen Sphäre wiederum unter ein höheres Ordnungsprinzip stellen:

Ernas Erfahrungshorizont ist geprägt vom Kampf des Menschen mit den Elementen und in wenigen Leitsätzen fixiert, mit denen sie den zivilisatorischen Verfallserscheinungen an Land begegnet: Das Schiff ist das Wichtigste, dem sich alles andere unterzuordnen hat, die Mannschaft hat dem Kapitän zu gehorchen und der Kapitän seine Verantwortung der Mannschaft gegenüber wahrzunehmen. Erna handelt als Agentin eines höheren Wertesystems, das die ewigen Gesetzlichkeiten des Lebens repräsentiert, und darf deshalb auch die gesellschaftliche Rangordnung ignorieren, wenn es darum geht, ihre Arbeitgeber wieder „auf den richtigen Kurs“ zu bringen. ${ }^{19}$

In Handlungsentwurf und Figurenanlage entspricht Hochbaums Film damit durchaus der allgemeinen Entwicklung des NS-Filmmelodramas zum Zeitpunkt seiner Produktion. Dem Genre kann für die Jahre 1937/38 unter der Last zunehmender ideologischer Inanspruchnahme eine gewisse kreative Stagnation attestiert werden, wie überhaupt die Mehrzahl deutscher Produktionen dieses Zeitraums vom Ausbleiben neuer „Motive, Themen und Erzählformen“ gekennzeichnet ist. ${ }^{20}$ Aufschlussreich ist dabei die Beobachtung, dass auch jenseits von EIN MÄDCHEN GEHT AN LAND verstärkt Frauen ins Zentrum der Figurenensembles rücken und nicht nur für Erna Quandt das Prinzip des „Lohns der guten Tat“ gilt: „Die Happy Ends dieser Filme sind häufig recht mühsam erarbeitet, mitunter ist eine Schwere präsent, die auf kommende Verhältnisse vorauszuweisen scheint.“21

Die zeitgenössische Genreentwicklung weist neben der „Konzentration auf Frauen-Geschichten“ zudem eine Tendenz zur Mischform des melodramatischen Heimatfilms auf, und zweifellos finden sich auch im ausgeprägten norddeutschen Lokalkolorit von Hochbaums Film „Genreelemente des Heimatfilms“.22 Jedoch handelt es sich, genauer besehen, eher um einen umgekehrten Heimatfilm, in dem das „Land“ die Rolle der potenziell verderblichen Großstadt und das „Meer“ den Status eines für die Protagonistin „verlorenen“ Elementarbereichs der moralischen Beherrschung der - eigenen wie sie umgebenden - Natur einnimmt.

19 Johannes Roschlau: EIN MÄDCHEN GEHT AN LAND (1938). In: Christoph Fuchs und Michael Töteberg (Hg.): Fredy Bockbein trifft Mister Dynamit. Filme auf den zweiten Blick. München 2007, S. 109-114, hier S. 113.

20 Astrid Pohl: TränenReiche BürgerTräume. Wunsch und Wirklichkeit in deutschsprachigen Filmmelodramen 1933-1945. München 2010, S. 148.

21 Pohl: TränenReiche BürgerTräume, S. 157.

22 Pohl: TränenReiche BürgerTräume, S. 158. 
Tatsächlich wirkt das soziale Gefüge an Land über weite Strecken wie „eine wilde See: sittenlos, zynisch, regellos. Das Mädchen verankert auf diesem Terrain die Moral." ${ }^{23}$

Auch in dieser Hinsicht entspräche der Film aber immer noch der allgemeinen Zeittendenz seines Genres ebenso wie einer in ihm lediglich auf besondere Weise exponierten zeitgemäßen Verhaltensnorm. Hieße der Regisseur von EIN MÄDCHEN GEHT AN LAND nicht Werner Hochbaum - „vaterlandsloser Gesell“24 und ,verdeckter Agent ästhetischer Opposition, der gegen die tümelnden Ekstasen des Tages wertkonservativ an Mitteln und Methoden alter Avantgarde festhielt“ ${ }^{\text {25 }}$-, man könnte es bei diesem Befund belassen. Der damals wie heute ihm anhaftende Ruf eines Avantgardisten mit sozialrealistischem Impetus lässt jedoch eine komplexere Positionierung vor dem Zeithorizont vermuten. ${ }^{26} \mathrm{Um}$ dieser Vermutung nachzugehen, sollen im Folgenden Hochbaums Anteil an der Stoffentwicklung bis zum fertigen Drehbuch, seine Rolle bei der öffentlichen Wahrnehmung des Films und nicht zuletzt sein Konzept der filmästhetischen Umsetzung des Handlungsentwurfs betrachtet werden. Gerade mit Blick auf den letzten Punkt geht es darum, die spezifische Entfaltung einer Bildsprache kenntlich zu machen und ins eingangs umrissene geopolitisch-ideologische Feld zu führen, die bei Hochbaum, glaubt man Karsten Witte, allzu oft durch das diskursive Raster der Filmgeschichtsschreibung fällt. ${ }^{27}$

\section{Verschiebungen}

EIN MÄDCHEN GEHT AN LAND basiert auf dem gleichnamigen Roman von Eva Leidmann, der, im April 1935 erschienen, bereits im Hinblick auf eine spätere Verfilmung geschrieben worden sein soll. Es spricht einiges dafür, dass hier „im voraus dramaturgische Arbeit geleistet“ ${ }^{28}$ worden ist, verfügte doch die Verfasserin als Mitautorin der Drehbücher zu PechmaRie (D 1934, Erich Engel), Das Mädchen Irene (D 1936, Reinhold Schünzel), Die Kreutzersonate (D 1937, Veit Harlan), LAND Der Liebe (D 1937, Schünzel) und FANNy ElsSLer (D 1937, Paul

23 Witte: Film im Nationalsozialismus, S. 144.

24 Klaus Kreimeier: Vaterlandsloser Gesell. In: Frankfurter Rundschau (13.04.1996).

25 Witte: Hochbaum, der Periphere: ein Zentraler, S. 6.

$26 \mathrm{Zu}$ Leben und Werk Hochbaums vgl. Elisabeth Büttner und Joachim Schätz (Hg.): Werner Hochbaum. An den Rändern der Geschichte filmen. Wien 2011.

27 Witte: Hochbaum, der Periphere: ein Zentraler, S. 5.

28 Georg Herzberg: EIN MÄDCHEN GEHT AN LAND. In: Film-Kurier 241 (14.10.1938). 
Martin) seit 1934 über Filmerfahrung, vor allem in der Adaption literarischer Vorlagen.

Schon 1929 hatte Eva Leidmann in einem kurzen Beitrag für den Hamburger Anzeiger die im Unterschied zum Theater weitaus deutlicher ausgeprägte Körperlichkeit des filmischen Mediums betont und zu deren Eindämmung den ,abstrakten Liebesfilm“ gefordert, „der uns die Auswirkung des Intellekts auf die Liebe, die vielgerühmte Sachlichkeit unserer Generation, der man so gern Gefühl absprechen möchte, demonstriert“. ${ }^{29}$ An gleicher Stelle lehnt sie wenig später den romantisch verklärten „amerikanischen Happyend-Film“ ab und stellt ihm jene „nicht glücklich endenden“ Manuskripte gegenüber, die aus „echter deutscher Ehrlichkeit“ heraus, „aus richtiggehender Überzeugung und menschlicher Einstellung“ auf eine glückliche Schlussfügung verzichteten. ${ }^{30}$ Beide von Leidmann in diesen Texten aus der Spätzeit des Stummfilms angestellten Überlegungen - die zunächst paradox anmutende Idee eines eher vernunft- als gefühlsgesteuerten Liebesfilms und die Wendung gegen ein romantisches Happy End zugunsten eines höheren Grads an Wirklichkeitsnähe - haben noch knapp zehn Jahre später in der Filmversion von EIN MÄDCHEN GEHT AN LAND ihre Spuren hinterlassen.

Obwohl Leidmann unmittelbar nach Erscheinen ihres Romans von der Ufa den Auftrag zur Ausarbeitung eines Filmtreatments erhält, ${ }^{31}$ dauert es bis Januar 1938, bevor die Umsetzung des Projekts in Angriff genommen und Werner Hochbaum als Regisseur verpflichtet wird. ${ }^{32}$ In der Hamburger Lokalpresse werden zwei Gründe dafür genannt, dass Leidmanns Filmentwurf „lange, lange in einer ,Mottenkiste‘ der dramaturgischen Abteilung“ geschlummert habe:

\footnotetext{
Es mag nicht nur an einer gewissen Scheu vor dem gefährlichen, dem unbekannten echt niederdeutschen Stoff in seiner Atmosphäre und seiner Haltung gelegen haben, daß man bisher niemandem diesen Stoff zur Gestaltung übergab; gleichermaßen ist dieses Buch mit einer ungewöhnlichen Schau von Menschen und Handlungen belastet, die erst heute nach der Rede des Propagandaministers über die Lebensnähe im Film erstrebenswerter geworden ist. $^{33}$
}

Im März 1938 arbeitet Hochbaum auf der Grundlage von Leidmanns Entwurf vor Ort in Hamburg am Drehbuch, das der Schriftstellerin durch ihren plötzlichen Tod

29 Eva Leidmann: Zwischen Film und Theater. In: Hamburger Anzeiger 16 (19.01.1929).

30 Eva Leidmann: Der amerikanische Happyend-Film. In: Hamburger Anzeiger 38 (09.03.1929).

31 Ufa-Vorstandsprotokoll vom 2.4.1935, Nr. 1071/7, Bundesarchiv Berlin, zit. nach: Roschlau: EIN MÄDCHEN GEHT AN LAND (1938), S. 109.

32 Vgl. Roschlau: EIN MÄDCHEN GEHT AN LAND (1938), S. 110.

33 Werner Kark: Zum ersten Mal: Hamburg im Spielfilm. In: Hamburger Tageblatt (10.03.1938). 
am 6. Februar 1938 „aus den Händen gerissen“ worden sei. ${ }^{34}$ Es ist davon auszugehen, dass die zum Teil erheblichen Änderungen in der Personen- und Konfliktstruktur des Stoffes, die der Film im Vergleich zum Roman aufweist, auf Hochbaum zurückgehen, sofern sie nicht korrigierenden Eingriffen der Reichsfilmdramaturgie zuzuschreiben sind. ${ }^{35}$

Auf Hochbaum, der seit 1935 häufig in Wien lebte, dürfte die veränderte Herkunft der Reedersfrau Lisa zurückgehen, die im Roman noch die Tochter einer neureichen Familie Gumpel aus dem sächsischen Weißenfels war:

Damit verschiebt Hochbaum den Akzent von der Verteidigung hanseatischer Tradition und Gediegenheit gegen neureiche Emporkömmlinge aus der sächsischen Provinz auf die Konfrontation zwischen dem Arbeitsethos und Standesdünkel der Hamburger Patrizier einerseits, der Offenheit und Lustbetontheit der „Wiener Lebensart“ andererseits. ${ }^{36}$

Änderungen in der Figurenkonzeption betreffen auch die Protagonistin des Films und ihr Verhältnis zu Jonny Hasenbein. Gegenüber ihrer literarischen Vorgängerin erfährt die Erna des Films eine deutliche Stilisierung als „Marien-Gestalt“, deren Zuneigung zu Hasenbein von Anfang an eher "fürsorgliche Züge“ trägt. ${ }^{37}$ Nicht zufällig avanciert sie am Ende „unter Beibehaltung ihrer Jungfräulichkeit zur Mutter von drei Kindern“. ${ }^{38}$

Noch deutlicher ist die charakterliche Neuakzentuierung der Figur Hasenbeins selbst. Tritt er im Film als selbständiger Fotograf auf, der die Schönheit der Frauen schon aus beruflichen Gründen zu rühmen hat, ist er im Roman bezeichnenderweise der Angestellte eines Schlachters. ${ }^{39}$ Dort hat er zudem von einer Jugendliebe einen siebenjährigen Sohn, den er unregelmäßig finanziell unterstützt, und (neben anderen „für die Kasse“) auch ein Mädchen „fürs Gemüt“, ${ }^{40}$ mit dem er eine gemeinsame Zukunft plant - jene Elfriede, die ihn im Film aus reiner Geldgier zu seinen Hochstapeleien anstiftet. Sein Interesse an Erna ist daher rein pekuniärer Art, wohingegen er ihr in der Filmversion ehrlich zugeneigt

34 Kark: Zum ersten Mal: Hamburg im Spielfilm.

35 In den meisten Produktionsberichten und Kritiken zum Film wird Hochbaums Beitrag zum Drehbuch hervorgehoben. Selbst dort, wo festgestellt wird, dass im Drehverlauf nur noch wenig am Buch geändert worden sei, wird lediglich darauf verwiesen, dass Eva Leidmann ,noch selbst mit Werner Hochbaum am Drehbuch gearbeitet“ habe. Vgl. Herzberg: EIN MÄDCHEN GEHT AN LAND.

36 Roschlau: EIN MÄDCHEN GEHT AN LAND (1938), S. 110.

37 Roschlau: EIN MÄDCHEN GEHT AN LAND (1938), S. 110.

38 Roschlau: EIN MÄDCHEN GEHT AN LAND (1938), S. 110.

39 Eva Leidmann: Ein Mädchen geht an Land. Roman. Berlin 1935, S. 69.

40 Leidmann: Ein Mädchen geht an Land, S. 184. 
zu sein scheint („Sie hätte ich früher kennenlernen müssen“), gar freiwillig auf ihr Geld verzichtet und außerdem noch den stillen Wunsch hegt, zur See zu fahren. Aus dieser veränderten Konstellation zwischen den beiden Figuren erklärt sich auch ein wichtiger Eingriff in die Plotstruktur. Im Roman trägt sich Erna bereits vor der Verhaftung Hasenbeins aus allgemeinem Lebensüberdruss und Sehnsucht nach ihrem toten Verlobten mit Selbstmordgedanken: „Der alten Elbe kann man sich ohne weiteres anvertrauen. Das ist so, als ob man heimkehrt. [...] Groterjahn ist nicht in der Elbe umgekommen; aber so weit weg ist die Elbe nicht vom Meer. “41 Der Moment der tiefsten Verzweiflung wird somit im Film kausal völlig anders verknüpft und an das Scheitern der Beziehung zu Hasenbein gekoppelt. Auch wird die lebensmüde Erna im Buch nicht von einem der Semmler-Kinder im Hafen aufgespürt, sondern von einer unbekannten Leidensgenossin bei ihrem Vorhaben mit den Worten gestört: „Regen, Musik, das Schiff, Sie und ich, - es ist wie im Kino. [...] Es gehört viel mehr Mut dazu, als man denkt, nicht? - Auf einmal hat man wieder nicht den Mut.“42

In der Anlage der Nebenfiguren sind ebenfalls signifikante Verschiebungen gegenüber der Romanvorlage festzustellen. Im Roman stirbt Tante Mariechen bereits kurz nachdem sie Erna die Anstellung bei den Sthümers - im Buch heißen sie „Stülcken“ - verschafft hat und hinterlässt ihr ein kleines Gartengrundstück mit dem sprechenden Namen „Garten Eden“. Und auch ihr Mann, Onkel Lüders, ist nach der Hälfte des Romans tot, weshalb beide nicht wie später im Film als genealogische Rahmung der Verbindung Ernas mit Friedrich Semmler und seinen Kindern dienen können. Semmlers Frau wiederum ist nicht bereits verstorben, als die Handlung einsetzt, sondern nimmt sich erst gegen Mitte des Romans aus Schwermut das Leben. Aus dem Postboten Semmler wird im Film ein Schiffszimmermann, der auf diese Weise zumindest beruflich mit der Seefahrt zu tun hat.

Im Unterschied zum Film wird der Erzählfortgang in Leidmanns Roman von drei wiederkehrenden Motiven strukturiert: den von Erna täglich abgerissenen Kalenderblättern, ihren Träumen und den Zukunftsprophezeiungen einer Freundin. Im Film fehlt diese Figur der Hobbywahrsagerin Frau Kienast, die für die abergläubische Erna als dritte Instanz der Wegweisung neben den Träumen und Kalendersprüchen fungiert. Im Roman halten Ernas Träume ihre anhaltende Sehnsucht nach dem toten Verlobten die gesamte Handlungszeit über präsent, im Film sind sie zu einer einzigen Traumsequenz verdichtet. Das Maß des Einblicks

41 Leidmann: Ein Mädchen geht an Land, S. 165.

42 Leidmann: Ein Mädchen geht an Land, S. 168. 
in das subjektive Innenleben der Protagonistin wird damit deutlich eingeschränkt.

Die Kalendersprüche bilden das einzig verbliebene strukturelle Erzählmotiv, dessen Herkunft und Inhalt gegenüber seiner Funktion im Roman jedoch nachhaltig verändert werden. Im Roman erhält Erna den Schifffahrtskalender zum ersten Weihnachtsfest nach ihrer Anstellung als Hausmädchen von Reeder Stülcken geschenkt, im Film bringt sie ihn aus ihrer Koje mit an Land. Im Roman wechseln nicht nur die Autoren, von denen die Sprüche stammen, der Schifffahrtskalender selbst wird zeitweise von einem Gartenkalender ersetzt, der Sentenzen u. a. von Rudolf Binding enthält. Der erste Spruch, den Erna im Roman liest, ist einem Goethe-Gedicht entnommen: „Seele des Menschen, wie gleichst du dem Wasser, / Schicksal des Menschen, wie gleichst du dem Wind!“433 Er deutet, wie andere Stellen im Roman auch, auf eine weiterhin stabil auf die See bezogene Heimatvorstellung Ernas. Sie wird anlässlich der Verlobung mit Groterjahn früh etabliert (,Und nun bekommt Erna doch einen Mann, und einen Schiffer noch dazu. Ihre Heimat bleiben Wasser, Wind, Schiff und Wolken“44) und drückt sich an Land vor allem als Heimweh aus: „Heimweh nach dem Schiff, nach Vater und Brüdern, nach Wasser und Wind. - Es gehört zu ihr wie Herz und Lunge. Es ist ihre Heimat.“45 Ihre Kurzformel lautet: „Elbe - - - Heimat!“46 Die innere Logik von Leidmanns Roman führt das drohende Verhängnis der Protagonistin folgerichtig darauf zurück, dass an Land die Sehnsucht nach Liebe, die Erna ,wie eine fiebrige Krankheit“ ${ }^{47}$ befällt, an die Stelle der Sehnsucht nach der Heimat zu treten droht, für die die Treue zum toten Verlobten lediglich als Chiffre steht. ${ }^{48}$

Die „Tagesparolen“ Gorch Focks, die „Erna in Momenten emotionaler Verunsicherung wie ein Orakel befragt“, ${ }^{49}$ leiten in der Filmversion des Romans hingegen eher dazu an, Heimat zu einer imaginären Größe zu sublimieren und für eine funktionierende Ökonomie des psychischen Haushalts mobilisierbar

43 Leidmann: Ein Mädchen geht an Land, S. 65.

44 Leidmann: Ein Mädchen geht an Land, S. 15.

45 Leidmann: Ein Mädchen geht an Land, S. 53.

46 Leidmann: Ein Mädchen geht an Land, S. 163.

47 Leidmann: Ein Mädchen geht an Land, S. 148. Der die Erzählerin an gleicher Stelle zu dieser Feststellung leitende Kalenderspruch lautet: „Liebe zaubert Lustpaläste, Treue baut ein einfach Haus, / Jene stürzen, dies hält feste bis in graue Zeiten aus.“

48 Vgl. Leidmann: Ein Mädchen geht an Land, S. 255: „Erna ist ruhig geworden. Kein Sturm tobt mehr in ihr, sie kann ihren geraden Kurs halten, - und dem toten Groterjahn die Treue. Nie wieder wird sie die warnende Stimme in ihrem Innern überhören; nie wieder vergessen, daß sie Frachtewer und kein Lustkutter ist. - Der Frachtewer Erna Quandt hätte allerdings mehr Ladung vertragen."

49 Roschlau: EIN MÄDCHEN GEHT AN LAND (1938), S. 113. 
zu machen. Die beiden im Film vollständig zitierten Passagen lauten dementsprechend: „Ich bin noch immer auf dem hohen Meer, / der Himmel über mir, die Dünen um mich her. / Noch immer schau ich groß nach meinen Segeln, / noch immer such' ich heißen Blicks mein Land, / bei Tag und Nacht, das Ruder in der Hand.“ Und: „Was das Leben nicht will geben, / Gibt der Traum, Segelraum.“ Gleichzeitig dienen die Sinnsprüche des als Weltkriegshelden und „literarische Ikone der niederdeutschen Bewegung ${ }^{\text {“50 }}$ geltenden Gorch Fock dazu, das Lokalkolorit des Films zu verstärken und dessen ideologischer Botschaft einen mythischen Subtext heroischer Selbstaufopferung zu verleihen.

\section{In den Bezirken des Alltags}

Hochbaums Beschäftigung mit dem Stoff wird in der Presseberichterstattung als Rückkehr zum Ausgangspunkt seiner Filmarbeit mit RAzzIA IN ST. PAULI (1932) gesehen, Hamburg als „Wahlheimat“ des gebürtigen Kielers in den Vordergrund gerückt. Bezeichnend für sein enges Verhältnis zur norddeutschen Metropole sei es zum Beispiel,

wenn er erzählt, daß er oftmals während seiner Wiener Tätigkeit vormittags ein Flugzeug bestieg, nachmittags in Hamburg eintraf, abends einmal wieder echtes Volkstheater auf dem Spielbudenplatz, in unserem Ernst-Drucker-Theater erlebte und am nächsten Morgen wieder seine Arbeit in den Wiener Ateliers aufnahm. ${ }^{51}$

Die in Hochbaum gesetzte Hoffnung bezog sich keinesfalls nur auf den Wahlhamburger, sie berief sich auch auf Hochbaums (zweifelhafte) Reputation als avantgardistischer Individualist unter den deutschen Filmregisseuren:

Einem Hochbaum trauen wir allerdings zu, daß er einmal von seinem besonderen Verhältnis zu dieser Stadt her dies Werk zu seiner Aufgabe macht, zum anderen aber auch aus der Erkenntnis, daß sich wieder nach langer Zeit von einem Außenseiter unseres Filmschaffens ein Film von programmatischer Bedeutung vorbereitet. Denn: diese Welt um Erna Quante [sic!] ist das Leben selbst, diese Charaktere gehen ihren Weg wie viele heute noch in allen Gassen und Straßen der Hafenstadt und ihre Konflikte stammen ausschließlich aus der Atmosphäre unseres Lebenskreises. ${ }^{52}$

50 Roschlau: EIn MäDCHEN GEHT AN LAND (1938), S. 113.

51 Kark: Zum ersten Mal: Hamburg im Spielfilm.

52 Kark: Zum ersten Mal: Hamburg im Spielfilm. Hervorhebungen im Original. 
Die Besetzung der Rollen wurde ebenfalls noch im März 1938 besorgt: Elisabeth Flickenschildt stand früh für die Hauptrolle der Erna Quandt fest, für die Rolle des Jonny Hasenbein war zunächst Harald Paulsen vorgesehen, bei der Figur Friedrich Semmlers wurde ursprünglich an Gustav Knuth gedacht. Jedenfalls wurde dies der Presse mitgeteilt, die zufrieden feststellte, alle drei besäßen „starke Bindungen an den niederdeutschen Lebensraum“ wie auch alle übrigen Rollen ,ausschließlich von Hamburger Schauspielern an den Hamburger Bühnen“ gespielt würden. ${ }^{53}$ Außenaufnahmen fanden ab Mitte Mai 1938 im Hamburger Hafen und im Hafen in Schulau statt, für den Juni waren Atelieraufnahmen in den Babelsberger Ufa-Studios angesetzt. ${ }^{54}$ Die Aufnahmen der Studioszenen sollten bis zum 23. Juni abgeschlossen sein, für die letzte Juniwoche waren, wie Produktionsassistent Erich von Neusser der Presse mitteilte, noch letzte Außenaufnahmen geplant. Hochbaum beruhigte die Branchenöffentlichkeit bei dieser Gelegenheit darüber, dass es sich bei EIN MÄDCHEN GEHT AN LAND keineswegs um einen „Dialektfilm“ handle. Der Dialog sei vielmehr so gehalten, „daß die Sprachmelodie einen norddeutschen Unterton erhält, daß aber weder plattdeutsch noch sogenanntes ,Missingsch“ (Mischung zwischen Hoch- und Plattdeutsch Hamburger Prägung)“ gesprochen werde. ${ }^{55}$ Anders als geplant zogen sich die Arbeiten im Studio noch etwas weiter in den Sommer hinein. Gegen Ende der Dreharbeiten brach Hochbaums langjähriger Regie-Assistent Rolf Niemitz am Set

53 Kark: Zum ersten Mal: Hamburg im Spielfilm. Auch wenn Letzteres in dem hier angedeuteten Umfang so nicht zutraf, rekrutierte Hochbaum doch die Darsteller der meisten Nebenrollen von Hamburger Bühnen, so z. B. Heidi Kabel für die Rolle von Ottos Braut Inge, Hans Mahler als Hein Groterjahn, Friedrich Schmidt als Kapitän Lüders oder Bruno Wolffgang als Jonnys Freund Alfred. Der junge Erich Feldt spielte Heini Semmler. Vgl. Bernhard Meyer-Marwitz: Hamburg wartet auf „seinen“ Film. Unsere Plattdeutschen drehen bei der Ufa. In: Hamburger Anzeiger (10.09.1938). 54 Vgl. [Anon.]: Hafenfilm mit Nebelpulver und Nebelbombe. Ufa und Terra filmen im Hafen heute Nacht gibt's eine dramatische Barkassenverfolgung. In: Hamburger Tageblatt (19.05.1938). Vgl. a. rg.: Im Hafen wird gefilmt! Spritschmuggel und EIN MÄDCHEN AN LAND. In: Hamburger Anzeiger (19.05.1938); Karlheinz Ressing: „Cap Arkona im strahlenden Licht“. Interessantes UfaExperiment im Hamburger Hafen. In: Film-Kurier 122 (27.05.1938). Ulrich J. Klaus datiert den Drehbeginn etwas zu spät auf den 20. Mai 1938. Vgl. Ulrich J. Klaus: Deutsche Tonfilme. Jahrgang 1938. Berlin und Berchtesgaden 1998, S. 125. Die Aufnahmen auf der Kommandobrücke des HornDampfers „Karlsruhe“ im Hamburger Hafen verliefen übrigens parallel zu Dreharbeiten am Reiherstieg-Zoll für die Terra-Produktion SCHATTEN ÜBER ST. PAULI (D 1938, Fritz Kirchhoff), in der Gustav Knuth tatsächlich in einer der Hauptrollen (des Barkassenführers Oschi Rasmus) agiert. Der Terra-Film trug zu diesem Zeitpunkt noch den Arbeitstitel „Wasserdroschke Junge Liebe“.

55 Zit. nach Ressing: „Cap Arkona im strahlenden Licht“. 
in Babelsberg nach einem Magenriss zusammen, an dem er kurz darauf verstarb. ${ }^{56}$ Am 16. September 1938 wurde der Film mit einer Länge von 2.646 Metern zur Zensur eingereicht und nach einer Kürzung auf 2.473 Meter unter Jugendverbot zur Vorführung zugelassen.

Die Vermarktung der Ufa hob weniger das Lokalkolorit als vielmehr die melodramatischen Züge des Films hervor, der als „dramatisches Schicksalsbild aus den unentdeckten Bezirken des Alltags“ angepriesen wurde, „ein dunkles und freudvolles Lied vom starken, tapferen Herzen einer Frau“ “. ${ }^{57}$ Neben dem Hinweis auf die verstorbene Verfasserin der literarischen Vorlage stand, noch vor der ausführlichen Charakterisierung der Rollen und ihrer Darsteller, der Regisseur im Mittelpunkt der Werbung. Als „Filmschöpfer von stärkster Kraft der Bildschilderung“ sei Hochbaum bekannt für sein „eigenwilliges Schaffen“. In diesem Fall hätte er zudem als Autor des Drehbuchs „in jedem Wort und in jeder Szene den Geist und die Atmosphäre eines eigenartig fesselnden, tief beeindruckenden Werkes“ geformt. „Sein Hamburg, sein St. Pauli“ habe er dabei „aller falschen Romantik entkleidet“. 58

Mit ihren Werbeplakaten (Abb. 1.1), vor allem aber in ihren Reklame-Ratschlägen für Kinobesitzer sah die Ufa vor, in Schaukästen auf die „Gegenüberstellung der gegensätzlichen Milieus des Films“ abzuheben:

Zeigen Sie im linken Feld und auf einem freundlich blauen Grund die Fotos des Schiffes, den Hafen, Seeszenen, Blankenese - im rechten Feld und auf einem stumpfroten Grund die Bilder von St. Pauli, also die Gruppenaufnahmen in der Gasse, die Kneipe der Elfriede, Tanz der Seeleute u.a. Links steht zwischen den Fotos die Zeile - die liebliche Elbküste bei Blankenese ... - rechts - Das grelle und dunkle St. Pauli ... - Auf einem als Mittelfeld dazwischen gestellten Kartonschild, auf dem beide Farbtöne gespritzt ineinander übergehen, steht der Text: ,... das sind die beiden Welten, zwischen denen das Mädchen Erna Quandt sich ihren Weg erkämpfte“. 59

Milieuspezifisch bzw. lokalfolkloristisch fielen auch die Empfehlungen zur Ausstattung des Kinofoyers aus. Angeregt wurde ein

Aufbau, welcher mit allen möglichen, gerade bei „Landratten“ Neugier erweckenden Gegenständen dekoriert wird - ein ausgestopfter Sägefisch, eine Schiffsglocke, ein Steuerrad,

56 Vgl. Werner Kark: Hamburger gehen voran in Babelsberg. In: Hamburger Tageblatt (10.09. 1938).

57 Ufa-Werbematerial, Deutsche Kinemathek - Museum für Film und Fernsehen, Schriftgutarchiv, Mappe „EIN MäDCHEN GEHT AN LAND“.

58 Ufa-Werbematerial.

59 „Ein Werber geht an Bord ...“, Ufa-Werbematerial, Deutsche Kinemathek - Museum für Film und Fernsehen, Schriftgutarchiv, Mappe „EIN MäDCHEN GEHT AN LAND“. 


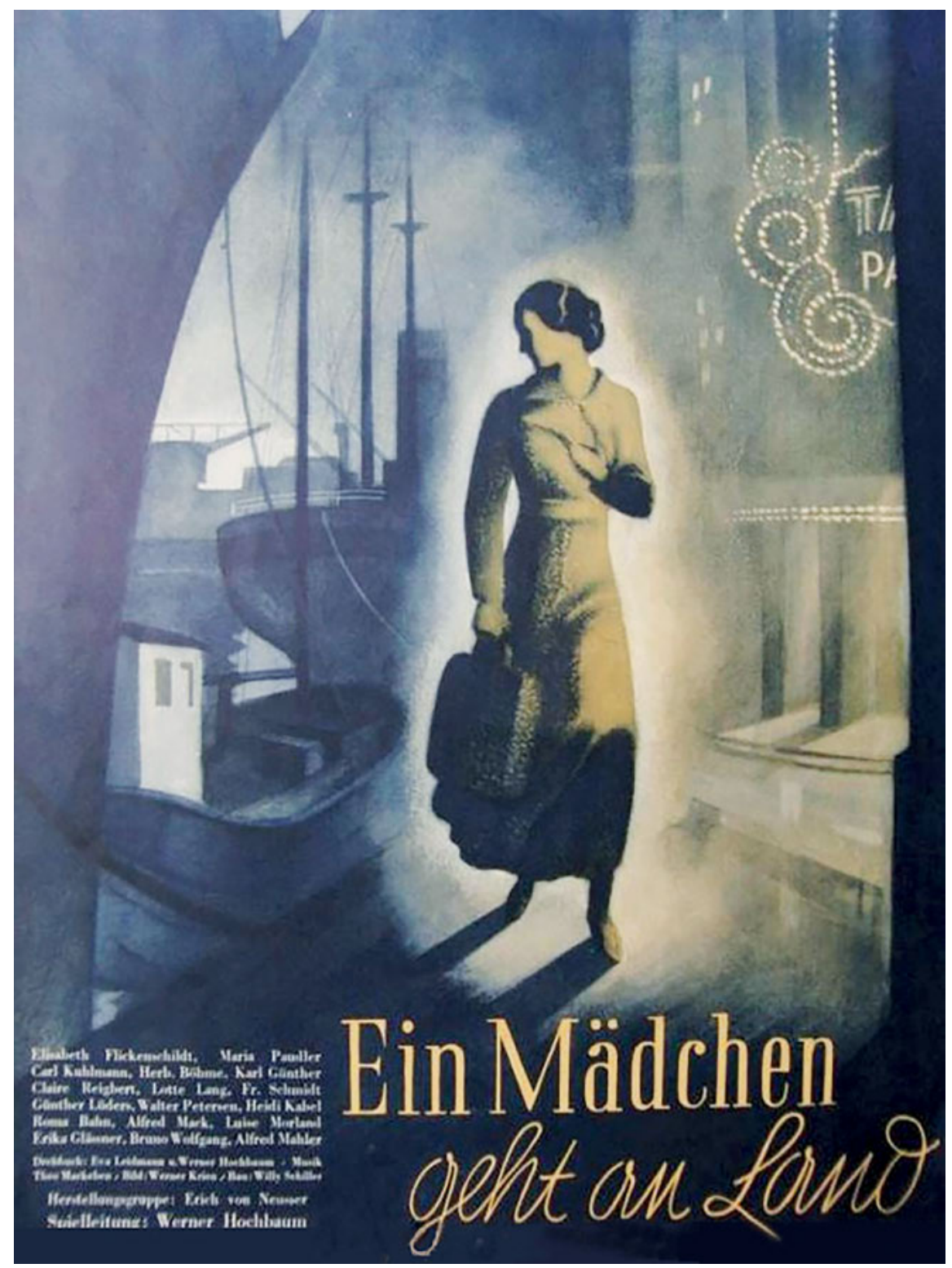

Abb. 1.1: Werbeplakat zu EIN MÄDCHEN GEHT AN LAND. 
Kompasse, Wimpel, Positionslampen, Taurollen, Segel, kleine Anker usw. und im Mittelpunkt vielleicht eine jener großen Flaschen, in denen ein Schiffchen eingebaut ist (sogenannte „Matrosenkunst“). ${ }^{60}$

Dazu „an den Wänden drei, vier hübsche Seestücke und einige gerahmte Fotos aus dem Film“, das schaffe eine „ganz angenehme Stimmung“. ${ }^{61}$

\section{Dinge hinter den Dingen}

In der Vorberichterstattung zur Hamburger Premiere des Films, die am 30. September 1938 zeitgleich im Lessing- und Passage-Theater stattfand, wird Hochbaum mit den Worten zitiert, er glaube, mit EIN MÄDCHEN GEHT AN LAND wieder Anschluss gefunden zu haben an DIE EWIGE MASKE (1935). Er glaube unverändert an „den Weg und die Mittel der ,Avantgardisten““, an die Gleichberechtigung der filmischen Form gegenüber den Erfordernissen des Stofflichen und Dramatischen. $\mathrm{Zu}$ erkennen sei dies nicht zuletzt daran, dass den Charakter auch seines neuesten Films die „Dinge hinter den Dingen“ ausmachen würden:

[...] eine glänzende visuelle Schau von St. Pauli, ein Alptraum des Mädchens Erna Quandt und ein anderer des Heiratsschwindlers Jonny Hasenbein. Hier experimentiert Hochbaum nicht nur, hier wächst eine notwendige filmische Übersetzung menschlicher Traumbilder organisch aus einer gelungenen Arbeit. $^{62}$

Auch die Fachzeitschrift Der Film zählt Hochbaum im Vorfeld der Berliner Premiere von EIN MÄDCHEN GEHT AN LAND - am 13. Oktober 1938 in den Ufa-Theatern Kurfürstendamm und Friedrichstraße - noch immer zu den Avantgardisten unter Deutschlands Filmregisseuren. Habe Hochbaum in seinen frühen Arbeiten die Möglichkeiten untersucht, „Gedankenverbindungen im Film mit der gleichen Geschwindigkeit und Buntheit wiederzugeben, wie sie sich im menschlichen Gehirn vollziehen“, und sich damit beschäftigt, welche „künstlerischen Perspektiven [...] der Film in seiner Überwindung von Raum und Zeit eröffnet“, so gelte das Hauptinteresse von reiferen Filmen wie MORGEN BEGINNT DAS LEBEN (1933), Vorstadtvarieté (1934) und Die ewige Maske einerseits der Milieuschilderung, andererseits der „Schilderung eines Seelenzustands auf rein visuelle

60 „Ein Werber geht an Bord ...“.

$\mathbf{6 1}$ „Ein Werber geht an Bord ...“.

62 [Werner Kark:] Hochbaum kehrt zum Experiment zurück. Von der RAzZIA über DiE EWige MASKE zu EIN MÄDCHEN GEHT AN LAND - ein Weg des guten Willens. In: Hamburger Tageblatt (24.09.1938). 
Art“. In diese doppelte Entwicklungslinie ließe sich nun auch der Film EIN MÄDCHEN GEHT AN LAND stellen, der insofern „viele seiner Regiegeheimnisse“ berge. ${ }^{63}$

Der „Adjudantur des Führers“ wurde der Film vom Propagandaministerium am 7. Oktober 1938 zugestellt. Am 4. November 1938 erhielt das Ministerium Rückmeldung über die Hitler an seinem Wohnsitz auf der Wolfsschanze in Berchtesgaden vorgeführten Filme. Nach DAS VERLEgEnHEITSKIND (1938, Peter Paul Brauer), einer anspruchslosen Gesellschaftskomödie, die ein „Ausgezeichnet“ erhielt, war EIN MÄDCHEN GEHT AN LAND neben dem Marika-Rökk-Vehikel EINE NACHT IM MAI (D 1938, Georg Jacoby) der einzige Film mit dem Vermerk, er sei von Hitler als „sehr gut“ bezeichnet worden. Die anderen der insgesamt 15 Titel blieben unkommentiert, wurden als „gut“ (FrAU SixTA, D 1938, Gustav Ucicky), „sehr amüsant!“ (Die ScheidungsReise, D 1938, Hans Deppe), „sehr schlecht“ (GelD FÄLlt Vom Himmel, D 1938, Heinz Helbig) oder gar als „unmöglicher Film“ (Zwei Frauen, D 1938, Hans H. Zerlett) bewertet. In zwei Fällen, bei SteputAT \& Co. (D 1938, Carl Boese) und MARIE AntoinetTe (USA 1938, W.S. Van Dyke) wurde die Vorführung abgebrochen bzw. von Hitler vorzeitig verlassen. Der zeitgleich entstandene zweite Hamburg-Film SCHATTEN ÜBER ST. PAULI erhielt von Hitler das Prädikat „schlechter Film“. ${ }^{64}$

Gemessen an derartigen Vorschusslorbeeren fiel das Presseecho auf die Hamburger, vor allem aber auf die Berliner Premiere von EIN MÄDCHEN GEHT AN LAND eher verhalten, ja zwiespältig aus. In seiner Besprechung im Hamburger Tageblatt wies Werner Kark noch einmal darauf hin, dass es bei der Ufa in Babelsberg seit jeher Vorbehalte gegenüber „hamburgischen Stoffen“ gegeben habe. Diese seien auch im vorliegenden Fall nicht vollständig zu überwinden gewesen. Schon der dem Film zugrundeliegende Stoff, „ein spannender, in manchen Dingen allerdings reichlich oberflächlicher Zeitungsroman“, habe „noch nicht die letzte, gültige Grundlage für einen echten Hamburg-Film abgeben“ können. Dies bliebe einer zukünftigen, „in tiefe menschliche und atmosphärische Bezirke“ greifenden dichterischen Arbeit vorbehalten. Hochbaum habe „einen industriellen Auftrag erhalten, den Leidmann-Roman zu verfilmen“, und dabei „ein gut Teil künstlerischer Konterbande an das neue Ufer seiner künstlerischen Arbeit hinübergetragen“. ${ }^{65}$

63 [Anon.]: Wegbereiter in filmisches Neuland. In: Der Film 41 (08.10.1938).

64 Reichsministerium für Volksaufklärung und Propaganda an die Adjudantur des Führers, 07.10.1938; SS-Obersturmführer Bahls an das Reichsministerium für Volksaufklärung und Propaganda, 04.11.1938, Bundesarchiv Berlin, Sign. NS 10/79789.

65 Werner Kark: Erster Vorstoß: EIN MÄDCHEN GEHT AN LAND. In: Hamburger Tageblatt (01.10. 1938). 
Der Film-Kurier würdigte nach der Berliner Erstaufführung immerhin, dass Hochbaum „mit diesem Film ein Werk von starker innerer Geschlossenheit“ gelungen, die „Atmosphäre [...] ausgezeichnet getroffen“ sei. Ein wesentlicher Einwand sei jedoch gegen ,die überlange und recht überflüssige Bildmontage über das Hamburger Nachtleben“ zu richten:

Sie paßt in ihrer Nervosität nicht zu dem ruhigen und sachlichen Stil dieses Films, sie treibt weder die Handlung vorwärts noch schafft sie eine benötigte Stimmung. Sie hätte einen Sinn, wenn sie das nächtliche Erleben des Paares Erna-Jonny ausdrücken würde, aber die [...] werden von dem Trubel St. Paulis kaum erfaßt. Diese Montage, in der sicher viel Arbeit steckt, ist ein Fremdkörper in diesem Film, eine Konzession an die glücklich überwundene Zeit, in der solche Schneidekunststücke Selbstzweck waren. ${ }^{66}$

Ausgerechnet Hochbaums Rückgriff auf ein charakteristisches Verfahren der filmischen Avantgarde, die Montage-Sequenz, empfand die NS-Filmbetrachtung über den vermeintlichen Stilbruch hinaus auch als formale Trivialisierung des Stoffes:

Die Schwermut und Tiefe des Romans, die stellenweise - so in der Verbundenheit der Menschen mit dem Meere und in dem schönen Glauben Ernas - in die Gebiete des Mystischen vorstößt, wird im Film kontrastiert durch eine Überrealistik der Darstellung, die wiederum auseinandergerissen wird durch eine sehr lange, vom Selbstzweck diktierte und mit dem Film und seinem Grundgedanken in keinem Zusammenhang stehende Montage, aus der uns aber auch einige in sie hineingestellte konkrete Aufnahmen wieder hinausreißen. Es entsteht so der vielleicht beabsichtigte Eindruck einer anscheinenden Stilunsicherheit, eines nervösen Schwankens, wie es auch die bisherigen Filme Hochbaums aufwiesen. Der plötzliche Schlag ins Sentimentale [...], mit dem als Kunstmittel hier und da gearbeitet wird, tangiert die Trivialität. ${ }^{67}$

Was als „Stilunsicherheit“ auf der formalen Ebene kritisiert wurde, erschien auf der Ebene der sozialen Milieuschilderung als Technik der intendierten Überzeichnung und Kontrastierung akzeptabel. Auf dieser Ebene unterstreiche Hochbaums Film bewusst die Gegensätze zwischen „vornehmen“ und „einfachen Leuten“, bürgerlicher Idylle und dem „wirbelnden Rausch und Glanz der Vergnügungslokale auf der Reeperbahn“. Manches sei dabei „etwas zu lang ausgespielt, um noch wirken zu können“, manches wiederum ginge „zu sprunghaft, so dass man nur mit Mühe folgen“ könne. Während ein Teil der Kritik Hochbaum für seinen als gekünstelte Formübung wahrgenommenen Avantgardismus zur Ordnung rufen zu müssen glaubte, vermisste ein anderer Teil an diesem insgesamt

66 Herzberg: EIN MÄDCHEN GEHT AN LAND.

67 Albert Schneider: EIN MÄDCHEN GEHT AN LAND. In: Lichtbild-Bühne 242 (14.10.1938). 
immerhin „beachtlichen Werk“ gerade dasjenige, „was man bei Hochbaum eigentlich erwartete: die avantgardistische Leistung“. ${ }^{8}$

\title{
Menschen, Gegenstände und Umgebungen
}

Worin hätte diese „avantgardistische Leistung“ im Kontext eines melodramatischen Genrefilms bestehen können? Hochbaum selbst hat im Vorfeld der Hamburger Premiere von EIN MÄDCHEN GEHT AN LAND Hinweise dazu gegeben. Am 29. September 1938, einen Tag vor der Uraufführung des Films, hält er auf Einladung der Hamburger Arbeitsgemeinschaft „Film“ einen Vortrag an der Universität Hamburg, auf den das Kinopublikum zuvor mit Diapositiven in ,allen Lichtspieltheatern“ der Stadt hingewiesen worden war:

\begin{abstract}
Die Großaufnahme, so sagte Hochbaum, stellte eine Revolution für den Schauspieler dar. Er sprach vom Einbruch des naturalistischen Films durch die Amerikaner und das moderne [sic!] Bemühen, diesen Naturalismus durch feinste atmosphärische Lichtmalerei zu einem filmkünstlerischen Stil zu entwickeln, ebenso wie von der Aufgabe des Filmschauspielers. Für ihn forderte er Beschränkung des Rollenfachs. Für den Darsteller, so sagte er, komme es nur darauf an, wie er im Leben handeln und fühlen würde. Die Wirkung im Film gehe also nur von der eigenen Persönlichkeit aus. ${ }^{69}$
\end{abstract}

Wie Presseberichten über die Veranstaltung zu entnehmen ist, schloss Hochbaum in seinen von Ausschnitten aus EIN MÄDCHEN GEHT AN LAND illustrierten Ausführungen an Überlegungen an, wie er sie ein Jahr zuvor in seinem Aufsatz „Technik als Mittel der künstlerischen Filmgestaltung“ angestellt hatte. ${ }^{70}$ Schon dort hatte er die Großaufnahme als revolutionäres Ausdrucksmittel in Bezug auf Schauspiel und Figurendarstellung gewürdigt, vor allem aber ihren Stellenwert zur Hervorhebung der Requisiten des Alltags betont, die dadurch „eine ungeheuer gesteigerte“, „symbolhafte Bedeutung“ erhielten. ${ }^{71}$ Als „filmische Symbole“ wiederum würde die dem Kamerablick und der „Tiefenregie“ der

68 [Anon.]: Legende im Hamburger Hafen. EIN MädCHEN GEHT AN LAND. In: Der Film 42 (15.10. 1938).

69 [Anon.]: Glanzvoller Start in Hamburg. EIN MÄDCHEN GEHT AN LAND. in: Film-Kurier 230 (01.10.1938).

70 Vgl. Elisabeth Holzkamm: EIN MÄDCHEN GEHT AN LAND erfolgreich uraufgeführt. In: LichtbildBühne 131 (01.10.1938).

71 Werner Hochbaum: Technik als Mittel der künstlerischen Filmgestaltung [1937]. In: Regina Schlagnitweit und Ralph Palka (Hg.): Die Filme von Werner Hochbaum. Wien 1996, S. 42-46, hier S. 42. 
Montage exponierte Dingwelt des Handlungsmilieus zur zeichenhaften Sprache eines „Filmsymbolismus“ beitragen, aus der heraus sich die „Möglichkeit, im Film seelische Vorgänge direkt zu zeigen“, eröffne. ${ }^{72}$ Dies bereite den Weg zur Überwindung einer rein naturalistischen Darstellungsweise (wie Hochbaum sie in seinem Hamburger Vortrag in Hollywood am Werk sah) hin zu einem ,absoluten Realismus“, einem vom „stillen Partner der ,Atmosphäre““ impressionistisch sublimierten Realismus der „optischen Akzente“ ${ }^{73}$ Als übergeordnete Aufgabe, als „die wahre Mission der deutschen Filmkunst [...] im Zeitalter des Impressionismus“ stelle sich die „Beseelung des Stofflichen - Beseelung des Bildes, des Tones und des schauspielerischen Ausdrucks über die technischen Maschinen hinweg“. In seinen eigenen Filmen ziele er daher auf „subtile Wirkungen“: „Impressionismus des Bildes, Atmosphäre des Tons.“74

Nimmt man Hochbaums Selbstzeugnisse aus dem zeitlichen Umkreis der Arbeit an EIN MÄDCHEN GEHT AN LAND zur Kenntnis, erscheint es kaum noch hinreichend, wie die zeitgenössische Kritik Spuren des Avantgardismus an vereinzelten Montagesequenzen auszumachen oder wie heutige Kommentatoren das Augenmerk auf den symbolischen Gehalt von Spiegelkonstruktionen, etwa bei den zentralen Gesprächen zwischen Erna und Jonny, zu lenken. ${ }^{75}$ Mit Gernot Böhme lässt sich „die Herstellung von Atmosphären“, um die es Hochbaum hier zu gehen schien, vielmehr als eine ästhetische Arbeit verstehen, die - ungeachtet der Rede vom Impressionismus - nicht punktuell, sondern strukturell funktioniert und synthetisch auf verschiedenen Gestaltungs- und Wahrnehmungsebenen operiert, von der filmisch je konkret gemachten „Präsenz von Menschen, Gegenständen und Umgebungen“ bestimmt. ${ }^{76}$ Als „gemeinsame Wirklichkeit des Wahrnehmenden und des Wahrgenommenen“ nehmen ästhetisch hergestellte Atmosphären - darin bestünde dann auch ihr „absoluter Realismus“ - den Charakter beides umfassender Räume an, ,insofern sie durch die Anwesenheit von Dingen, von Menschen oder Umgebungskonstellationen, d. h. durch Ekstasen ,tingiert‘ sind. Sie sind selbst Sphären der Anwesenheit von etwas, ihre Wirklichkeit im Raume. “77

Es zeigt sich: Erst in der ästhetisch hervorgebrachten „ekstatischen“ Wirklichkeit im Raum wird die auf der Handlungsebene von Hochbaums Film dezisionistisch eingehaltene Trennung von Land und Meer porös. Am offenkundigsten

72 Hochbaum: Technik als Mittel der künstlerischen Filmgestaltung, S. 42f.

73 Hochbaum: Technik als Mittel der künstlerischen Filmgestaltung, S. 45.

74 Hochbaum: Technik als Mittel der künstlerischen Filmgestaltung, S. 46.

75 Vgl. Roschlau: EIN MÄDCHEN GEHT AN LAND (1938), S. 111.

76 Gernot Böhme: Atmosphäre. Essays zur neuen Ästhetik. Frankfurt am Main 1995, S. 25.

77 Böhme: Atmosphäre, S. $33 \mathrm{f}$. 

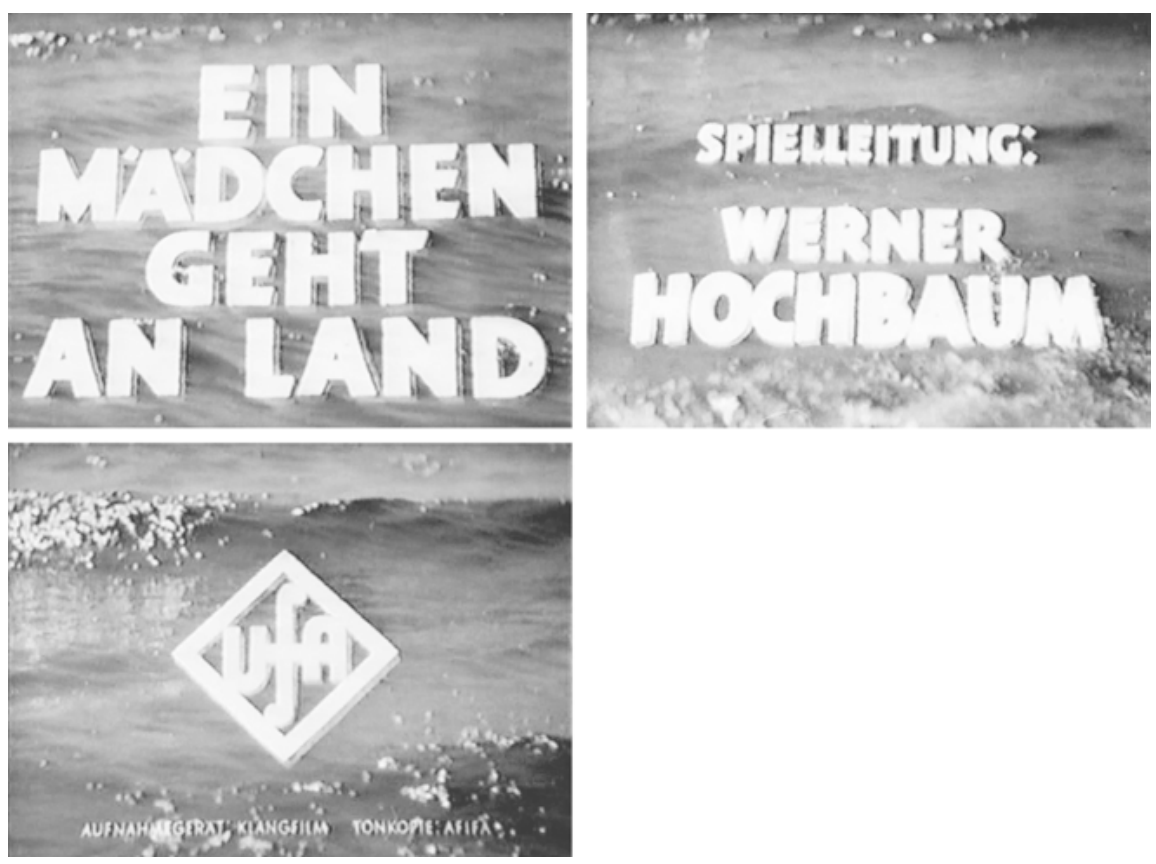

Abb. 1.2: Titelsequenz von EIN MÄDCHEN GEHT AN LAND.

geschieht dies auf der Tonspur, auf der „das ständige Tuten der Nebelhörner“ sämtlichen Schauplätzen eine gemeinsame akustische Signatur verleiht, die „den Film wie ein Generalbaß“ “ durchzieht. ${ }^{78}$ Exemplarisch vorgeführt wird dieses Verfahren, das quer zur Geopolitik der Handlungskonflikte einen vexierenden ästhetischen Erfahrungsraum schafft, in der Exposition von EIN MÄDCHEN GEHT AN LAND. Im Hintergrund der Vorspanntitel sieht man zunächst das Meer, dessen gleichmäßiger, den melodischen Lauf der Musik rhythmisch begleitender Wellengang den Bildraum vollständig ausfüllt. Die Wellenkämme brechen glitzernd im Dämmerlicht zur Kamera hin und bilden einen rhythmischen Kontrapunkt zum Wechsel der über ihnen sichtbar werdenden Schrift (Abb. 1.2).

Das Widerspiel dieses gleichmäßig bewegten Glanzes prägt noch die erste Dialogszene unter Deck, in der Groterjahn mit Ernas Vater die anstehende Hochzeit bespricht. Das im Hintergrund auch aller folgenden Szenen unter Deck präsent gehaltene Lichtspiel verleiht dem Handlungsraum eine fluide Anmutung, die ihn als der Sphäre des Meeres zugehörig ausweist. Am intensivsten wirkt diese atmo-

78 Roschlau: EIN MÄDCHEN GEHT AN LAND (1938), S. 112. 

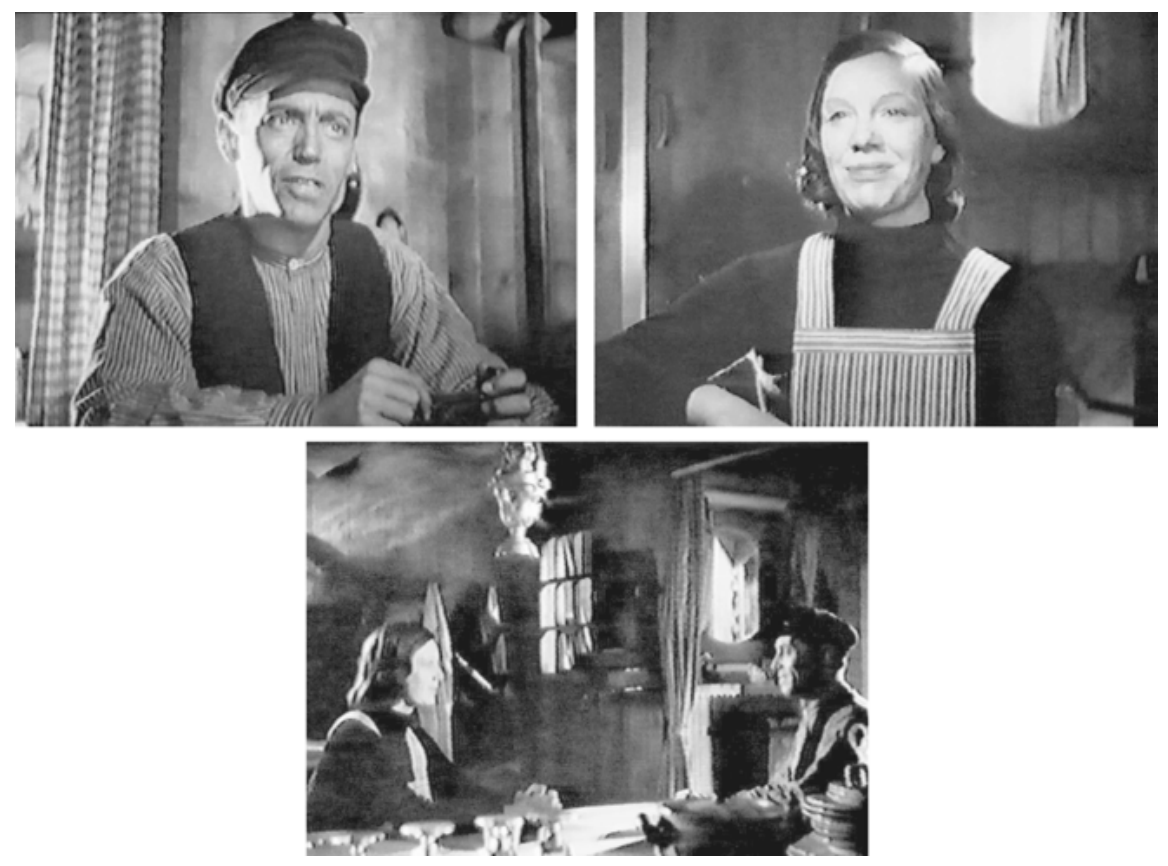

Abb. 1.3: Erste Dialogszene.

sphärisch vexierende Raumkennzeichnung, wenn Erna und Groterjahn anschließend in einer Wechselfolge halbnaher Einstellungen ihr einziges Vieraugengespräch über die gemeinsame Zukunft führen (Abb. 1.3), bevor sie sich trennen, um beide auf getrennten Schiffen in See zu stechen.

Es folgt die Einführung von Blankenese als erstem Handlungsschauplatz an Land. Als sei die Kamera vom selben Wind bewegt wie die schmalen Birken, die sie uns zeigt, gleitet sie in einem horizontalen Schwenk vom Namenszug des im Garten stillgelegten Seglers von Onkel Lüders hinüber zum Haus Semmlers, der soeben aus der Tür tritt, um mit seinem auf der Bank vor dem Fenster sitzenden Nachbarn über die heraufziehende Brise zu sprechen. Während auf Lüders schräg von hinten das gleichmäßig von innen durch die Scheiben dringende Licht fällt, ist Semmlers Gesicht vom dynamischen Helldunkel des Licht- und Schattenwurfs überlagert, den der Wind in den Zweigen der Bäume erzeugt (Abb. 1.4). Der „schicksalhafte“ Wind, der zuvor schon das expressive Lichtspiel unter Deck der „Katharina Quandt“ bedingt hat und aus dem sich der fatale Sturm entwickeln wird, in dem Ernas Verlobter umkommt, verbindet, auf diese Weise ins Visuelle transponiert, die bisher gesehenen Schauplätze und fasst die Protagonisten unter ein gemeinsames Movens der anhebenden Erzählung. 


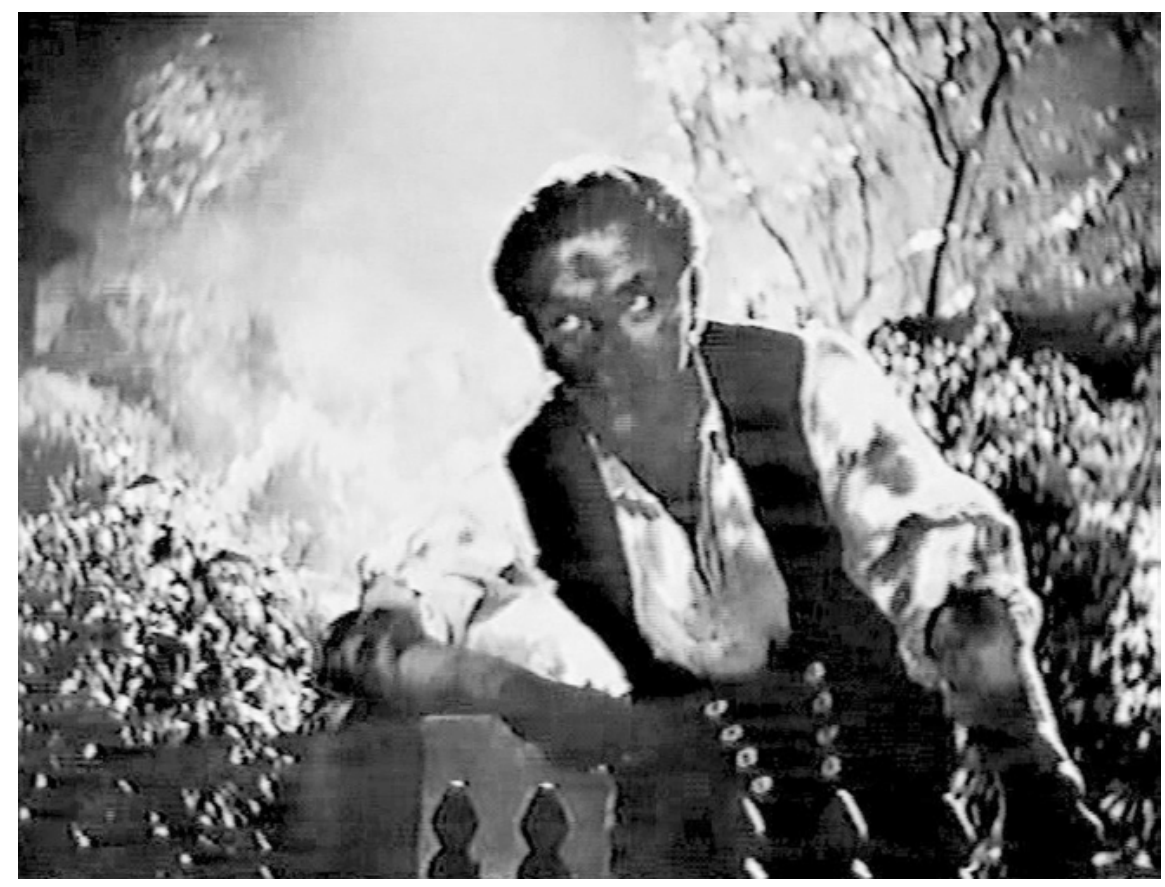

Abb. 1.4: Dynamisches Helldunkel.

Diese Bewegung setzt sich fort, angetrieben von einer prononciert dynamischen Kameraarbeit, die Karsten Witte mit Blick auf MoRGEN BEGINNT DAS LEBEN nicht umsonst als „fluide“ bezeichnet hat. ${ }^{79}$ Hier dient sie dazu, uns die Topografie der Blankeneser Handlungsschauplätze in ihrer Analogie zur Anordnung von Brücke und Kajüten vor Augen zu führen: Die Villa der Sthümers liegt, wie ein weiterer Kameraschwenk als Szenenübergang enthüllt, nur wenige Meter auf einer Anhöhe oberhalb der beiden weitaus kleineren Häuser des Schiffszimmermanns Semmler und des Schiffsbedarfshändlers Lüders.

Von außen nähert sich der Kamerablick auf das mit Gardinen verhangene Fenster des Wohnzimmers, in dem Lisa Sthümer am Flügel sitzt. Die Kamera springt ins Zimmer hinein, als die Reedersfrau vom Zimmermädchen in ihrem Spiel unterbrochen wird und die Mitteilung erhält, dass Herr Sthümer heute Nacht nicht mehr nach Hause zurückkehren wird. Das folgende Gespräch über die Schwierigkeiten der Eingewöhnung im Norden wird immer wieder von Schiff-

79 Witte: Hochbaum, der Periphere: ein Zentraler, S. 8: „Die Kamera panoramiert, schwenkt, tanzt durch den Raum, als stünde hinter ihr eine Erzählfigur, die den Raum horizontal vermißt.“ 

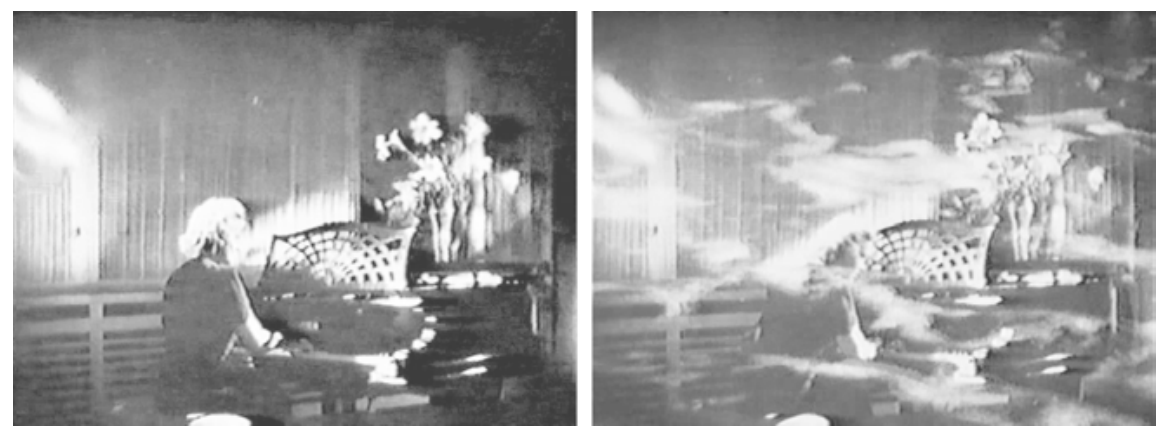

Abb. 1.5: Klavier im Wellengang.

fahrtsgeräuschen punktiert, die von der nahen, konstant im schemenhaften Hintergrund sichtbar gehaltenen Elbe in das Zimmer dringen, weshalb das Fenster auf Bitten der Hausherrin geschlossen wird. Nachdem auch das Radio, in dem lediglich unerwünschte Schiffsmeldungen $\mathrm{zu}$ hören sind, kurzerhand wieder ausgeschaltet wurde, setzt sich Lisa Sthümer abermals an den Flügel und beginnt mit einem ersten temperamentvollen Griff in die Tasten erneut zu spielen.

Die dramatisch anschwellende Melodie wird mitgenommen in eine Montagesequenz von bedrohlich dräuenden Wolken und vom Wind gepeitschten Bäumen, bevor der Kamerablick wieder just zu dem Augenblick ins Wohnzimmer der Sthümers zurückkehrt, als die Gartentür vom heftigen Wind aufgestoßen wird. Die Hausherrin lässt sich dadurch nicht beirren. Ganz im Gegenteil: Ihrem leidenschaftlichen Spiel wird per langsam hervortretender Doppelbelichtung das Panorama hohen Wellengangs auf See unterlegt. Für einige Sekunden fügen sich die tosende See und das tosende Spiel, das instrumental aus dem Off zu symphonischer Stärke anschwillt, zu einer einzigen Wahrnehmungsfigur (Abb. 1.5).

Schließlich setzt sich die aufgewühlte See im Bildkader durch und eröffnet eine visuelle Kaskade ähnlicher Ansichten. Sie führen schließlich zu Sturmszenen an Bord der „Katharina Quandt“, auf der Erna zusammen mit Vater und Brüdern gegen den heftigen Seegang zu kämpfen hat. Die Exposition endet damit, dass Erna auf Geheiß ihres Vaters das Steuer übernimmt und - so wird zumindest im Schlussbild und der folgenden, am Morgen nach dem Sturm an Bord spielenden Szene suggeriert - das Schiff sicher durch den Sturm lenkt. 
Ästhetisch wird in der Exposition von EIN MäDCHEN GEHT AN LAND ein Prozess der Raumdiffusion in Gang gesetzt, der Omnipräsenz, Vielgestaltigkeit und dynamische Heterogenität als grundlegende mediale Eigenschaften des Fluiden in die Register des Sinnlich-Symbolischen überträgt. ${ }^{80}$ Sie bilden im weiteren Verlauf des Films die Grundlage für ein inszenatorisches Kalkül, das aus den heterotopischen Wechselverhältnissen zwischen Fluidem und Festgefügtem variierende atmosphärische Aggregatzustände gewinnt. In der Szene etwa, in der Erna an Bord der „Katharina Quandt“, wo sie mit ihrer Familie soeben um den Mittagstisch versammelt war, die Mitteilung vom Tode Groterjahns erhält, setzt die Schuss-Gegenschuss-Montage die beiden Wahrnehmungssysteme in bildhafter Polarität gegeneinander, so wie zuvor im Gespräch zwischen Friedrich Semmler und Onkel Lüders: Das statische Tableau der noch immer um den Tisch versammelten Familie wird mit einer Großaufnahme Ernas vor dem Hintergrund vexierender Lichtreflexe kontrastiert. Sie verleihen einer inneren Gemütsbewegung äußeren Ausdruck, deren Resultat Erna - in Mimik und Gestik dem Anschein nach ungerührt ${ }^{81}$ - ihrer Familie verkündet: „Ich kann jetzt nicht an Bord bleiben, Vater, das weißt du selbst. Ich geh' an Land.“

An Land wiederum entwirft der Film Räume, die auf ähnliche Weise von Mustern der ästhetisch-atmosphärischen Differenz und Diffusion gezeichnet sind: Während die Kammer Ernas im Haushalt der Sthümers mit ihren Holzplanken, geschwungenen Formen und einem rundlich eingefassten Fenster seine neue Bewohnerin zu Recht an ihre Koje auf der „Katharina Quandt“ erinnert, sind Architektur und Einrichtung aller anderen großzügigen Zimmer, Säle und Flure von symmetrisch angeordneten Formen und arabesk verspielten, mal gitterförmigen, mal floralen Ornamenten geprägt. Blankenese mit der Sthümer-Villa, den Häusern der Familien Lüders und Semmler ist somit nicht nur topografisch, sondern auch atmosphärisch zwischen Stadt, Land und Meer angesiedelt. Nicht von ungefähr wird Erna am Ende in diesem Zwischenbereich ihre neue Heimat finden.

Vollends wird die atmosphärische Zwischenstellung Blankeneses im Kontrast zu den eigentlichen Räumen der Stadt lesbar: Hochbaums Bilder von ihr sind durchsetzt mit Netz- und Gittermotiven, die sich in der Straßenarchitektur ebenso finden wie in den Schatten auf den Figuren, vor allem aber in Elfriedes Kneipe mit ihren Girlanden und Gliederketten-Vorhängen und Jonnys darüber gelege-

80 Vgl. Franziska Heller: Filmästhetik des Fluiden. Strömungen des Erzählens von Vigo bis Tarkowskij, von Houston bis Cameron. München 2010, S. 56.

81 Inszeniert ist hier ein Spiel der Diffusion von Innen und Außen, dessen Metaphorik auch im Dialog aufgerufen wird, wenn Jonny bei ihrer ersten Begegnung von Erna behauptet: „Solche Augen haben nur Seeleute. Da spiegelt sich das ganze Meer drinnen.“ 
nem, vom Schattenwurf der Jalousien schraffiertem Zimmer auf St. Pauli. „Eine Stadt ist wie ein Netz. Fäden laufen kreuz und quer“, 82 liest man in Leidmanns Roman. Hochbaum lässt die Netzmetapher selbst noch in das erste Rendezvous zwischen Erna und Jonny hineinspielen, bei dem der Frauenheld im Café per Tischtelefon permanent von anderen jungen Damen angerufen wird. Als solche bildet sie eine weitere Brücke zwischen Land bzw. Stadt und Meer, indem sie das urbane Geflecht von Kommunikation, Unterhaltung und Verführung mit dem maritimen Fangnetz des Fischers figurativ zur Deckung bringt.

In die idyllisch-piktoriale Form eines statischen Figurentableaus gepresst, scheinen mit dem Schlussbild des Films, den Gesetzen des Melodramas gehorchend, die von Hochbaum mobilisierten atmosphärischen Regime einmal mehr auf die Familie als das einzig wahrhaft Festgefügte hin aufgelöst und metaphorisch mit der Rede vom „sicheren Hafen“ endgültig besiegelt. Im Abspann gilt der letzte Blick dann jedoch wieder dem offenen Meer, bevor über den aus dem Vorspann bekannten Bildern endlos rollender Wellen die Einblendung „Ende“ $\mathrm{zu}$ lesen ist (Abb. 1.6). Diese paradoxe Fügung behauptet das Fluide als ein dem Filmischen zutiefst verwandtes Prinzip der beständigen Veränderung, dessen zeitlicher Horizont potenziell unendlich ist und das als Raumkategorie auf eine „innere Unermesslichkeit“ hindeutet. ${ }^{83}$ So endet ein Film, der, das Loblied aufs irdische Glück singend, zugleich dessen Grenzen aufzuzeigen versteht.

„Der Mensch kann nur dann gut und in Sicherheit leben, wenn er den Kampf zwischen Erde und Wasser für beendet (zumindest für beherrscht) hält", liest man bei Gilles Deleuze an eher abgelegener Stelle. ${ }^{84}$ Der Satz könnte auch von Carl Schmitt stammen. Deleuze fügt seiner Feststellung allerdings eine Bemerkung hinzu, wie man sie bei Schmitt vergeblich suchen dürfte: „Diese beiden Elemente nennt er gern Vater und Mutter, wobei er die Verteilung der Geschlechter der Laune seiner Träumerei überläßt.“85

82 Leidmann: Ein Mädchen geht an Land, S. 140.

83 Gaston Bachelard: Poetik des Raumes [1957]. Frankfurt am Main 2007, S. 187. Vgl. Heller: Filmästhetik des Fluiden, S. $66 \mathrm{f}$.

84 Gilles Deleuze: Ursachen und Gründe der einsamen Inseln. In: Ders.: Die einsame Insel. Texte und Gespräche von 1953 bis 1974. Frankfurt am Main 2003, S. 10 -17, hier S. 10. Es handelt sich dabei um einen in den 1950er Jahren entstandenen Text, der zu Lebzeiten von Deleuze unveröffentlicht geblieben ist.

85 Deleuze: Ursachen und Gründe der einsamen Inseln, S. 10. 


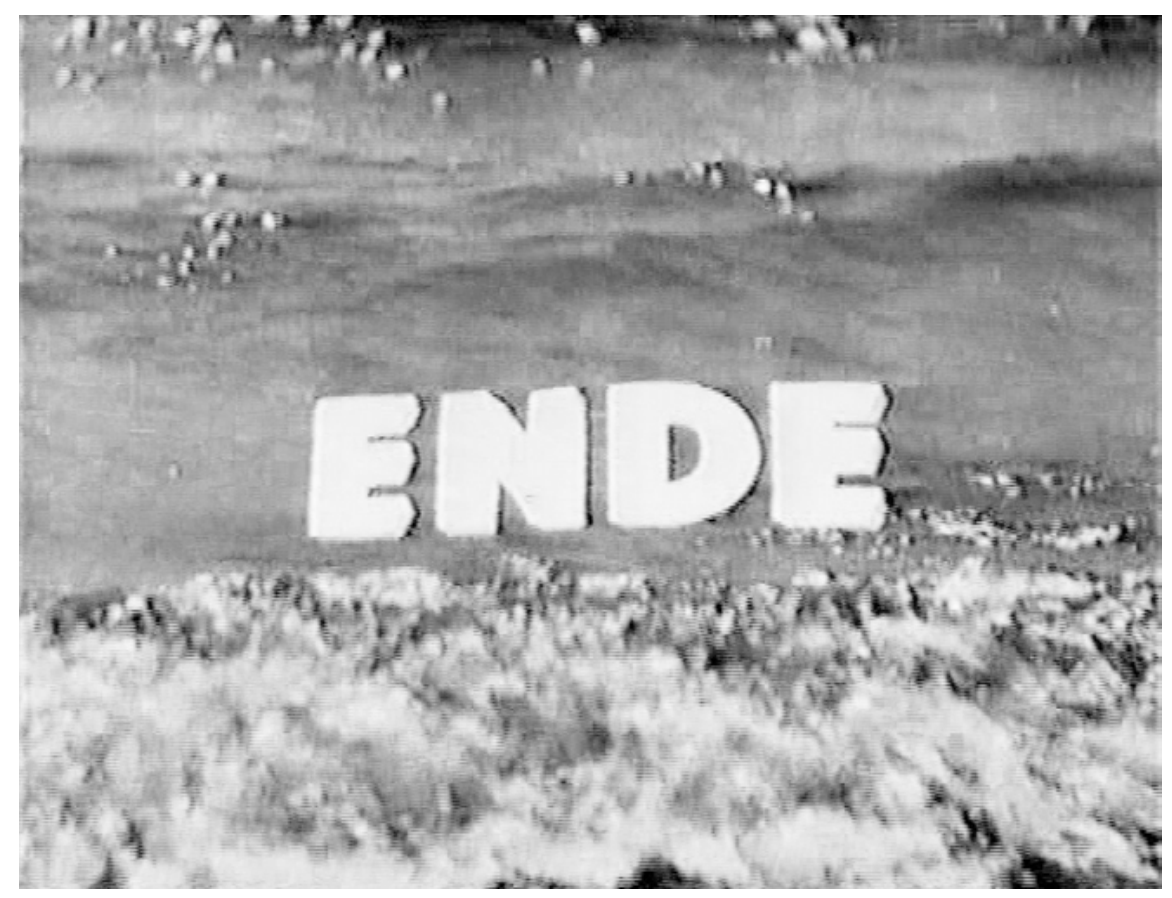

Abb. 1.6: Schlussbild von EIN MÄDCHEN GEHT AN LAND. 